$\mathscr{L}$

\title{
Fertilizer Feeding Mechanism and Experimental Study of a Spiral Grooved-Wheel Fertilizer Feeder
}

\author{
Zhang Liping ${ }^{1}$, Zhang Lixin ${ }^{1, *}$ and Zheng Weiqiang ${ }^{2}$ \\ ${ }^{1}$ College of Mechanical and Electrical Engineering Shihezi University, Shihezi 832000, China \\ ${ }^{2}$ College of Mechanical Engineering, Xinjiang University, Urumchi 830046, China
}

Received 9 September 2018; Accepted 22 December 2018

\begin{abstract}
Outer grooved-wheel fertilizer feeders are extensively used for the application of solid fertilizers. As a key structure of the fertilizer feeding apparatus, this type of feeder's performance directly affects fertilizer feeding quality. Given that the teeth ridge of the traditional outer straight grooved-wheel fertilizer feeder is parallel to the axis, the teeth ridge and groove appear in a staggered manner during fertilizer feeding, and the fertilizer appears a pulsation phenomenon that affects the uniformity of fertilizer feeding. Therefore, for the fertilizer feeding pulsation problem caused by the structure of the outer straight grooved-wheel fertilizer feeder during fertilizer feeding, the spiral grooved-wheel was used in this study to replace the straight grooved-wheel. Design optimization was performed on the key structural parameters of the spiral grooved-wheel fertilizer feeder, and the uniform fertilizer feeding mechanism of the spiral grooved-wheel was studied using particular discrete element. Then, an experimental comparison and analysis of the fertilizer feeding performance of the two grooved-wheel types were implemented. Results showed that under similar conditions, the fertilizer feeding quantity of the spiral grooved-wheel was higher than that of the straight grooved-wheel when the helix angle was $60.83^{\circ}$. Through this mechanism, the spiral grooved-wheel was always a constant axial teeth ridge section participating in the fertilizer feeding process. The uniformity of fertilizer feeding is improved. The fertilizer feeding uniformity of the spiral grooved-wheel fertilizer feeder is much better than that of the straight grooved-wheel fertilizer feeder when the revolving speed is low. This study is important for mechanical-structural optimization of solid fertilizer feeders and improvement of fertilizer feeding precision.
\end{abstract}

Keywords: Spiral grooved-wheel, Pulsatility,Helix angle,Uniformity

\section{Introduction}

Fertilizers exert important effects on the increase in crop yields. Unreasonable fertilizer application causes energy loss and results in nutrient imbalance, soil fertility decline, environmental pollution, and so on. At present, the quantity of chemical fertilizers applied in China is at a high level, but fertilization techniques are relatively inefficient and lack proper agricultural fertilization equipment. Hence, economical, reasonable, and scientific fertilization can not be realized. The outer straight grooved-wheel fertilizer feeder, which is extensively used for the application of solid fertilizers at present, has many advantages, such as simple structure and favorable universality, but the pulsation phenomenon appears when the fertilizer amount is small and the revolving speed of the fertilizer feeder is low because of structural limitations [1-3]. Therefore, the feeder can not guarantee fertilizer feeding uniformity, and this inability affects fertilizer feeding precision and causes fertilizer wastage and environmental pollution.

The commonly used methods of improving the fertilizer feeding uniformity of fertilizer feeders include control theory and discrete element methods. The former uses control theory to realize parameter optimization of the control system and thus improve fertilizer feeding precision

*E-mail address:_lyzzyjs2010@163.com

ISSN: $1791-2377$ @ 2018 Eastern Macedonia and Thrace Institute of Technology. All rights reserved. doi:10.25103/jestr.116.14
[4-7], but it does not radically solve the fertilizer feeding non-uniformity phenomenon caused by fertilizer feeders. The latter uses the discrete element method to optimize key parameters of the fertilizer feeder, and it is direct and universal. Researchers have used the discrete element method to study the parameters of the grooved-wheel fertilizer feeder, such as diameter, effective working length, revolving speed, and groove number [2,8], but the method cannot solve the pulsation problem under low revolving speeds and small feeding quantities. Only a few studies have been conducted on the influence of the grooved-wheel's helix angle on fertilizer feeding uniformity. Therefore, studying the influence of helix angle on fertilizer feeding uniformity is important in achieving uniform fertilizer feeding and improving the mechanical precision of fertilizer feeders.

\section{State of the art}

Studies on fertilizer feeding pulsation and non-uniformity of the grooved-wheel fertilizer feeder conducted by foreign scholars have focused on the relationships of fertilizer feeding uniformity with grooved-wheel diameter, effective working length, grooved-wheel type, groove number, and number of revolutions. For example, Guler et al. [9] obtained the effective working length, diameter, and number 
scope of revolutions of a spiral sheath with a uniform arrangement of alfalfa seeds, but they did not study the influence of helix angle on uniformity. Ozturk et al. [10] experimented on the effects of groove pattern length, revolving speed, and groove pattern shape on wheat flow uniformity by using the Taguchi optimization method and established the order of importance of these influence factors. however, they did not study other influence factors. Valentin et al. [11] examined the influence of groove direction on the uniformity of small seed distribution under certain diameter, groove number, and length conditions. Maleki et al. [8] found that fertilizer feeder uniformity increases with the outer diameter of the spiral grooved-wheel, groove depth and width, spiral quantity, and revolving speed, but they did not study the influence of helix angle on uniformity. Ning et al. [12] confirmed that the working parameters of the grooved-wheel contributed to the improvement of the fertilizer feeding performance of the grooved-wheel, but they did not consider the influence of helix angle on uniformity. Kara et al. [13] discovered that groove diameter, helix angle, drive roll length, and fluted roller velocity significantly influence fertilizer flow, uniformity, and velocity. However, they did not provide the concrete influence laws of helix angle on fertilizer feeding uniformity, although they mentioned the grooved-wheel helix angle. Chinese scholars have conducted many studies on fertilizer feeding uniformity, which concentrated on using the control system to change the revolving speed of the outer groovedwheel or revolving speed-opening control sequence or to change the mechanical component structure in order to realize accurate and automatic variable rate fertilization and solve the contradiction between fertilizer feeding precision and uniformity. However, only a few studies have focused on the relationship between fertilizer feeding uniformity of the spiral grooved-wheel and helix angle. For example, Liu [4] proposed a method to resolve the limited operational capability of a dual-variable rate fertilizer feeder-board computer with fertilization precision and uniformity. Wang et al. [14] designed a variable rate fertilizer distributor that uses an ordinary outer grooved-wheel as a fertilizer metering device and adjusted the fertilizer amount by adjusting the revolving speed of the outer grooved-wheel. Zhang et al. [15] designed a fertilizer distributor that achieves automatic variable rate fertilization by controlling the revolving speed of the fertilizer feeding shaft on the fertilizer distributor. Several researchers have indirectly improved fertilizer feeding uniformity through design optimization [16-18] of mechanical components, such as fertilizer mixer, fertilizer feeding tube, and uniform fertilizer distributor by using discrete elements. Studies of Chinese scholars have improved fertilizer feeding uniformity to a certain degree, but these studies increased the complexity of the variables of the control system and mechanical structures and the improvement cost. Therefore, on the basis of existing spiral seed-metering devices and spiral fertilizer feeding devices [19-21], the spiral grooved-wheel was used in the current study to replace the straight grooved-wheel fertilizer feeder. The key structural parameters and fertilizer feeding mechanism were studied. A comparative test was conducted on the fertilizer feeding performance of the two groovedwheel types under different working conditions by using a fertilizer feeding test bench, thereby providing a basis for fertilizer feeding uniformity and precision.

The remainder of this study is organized as follows. Section 3 presents the structural design and modeling of the spiral grooved-wheel fertilizer feeder, the fertilizer feeding process simulation, and the mechanism analysis. Section 4 analyzes the simulation results of the fertilizer feeding performance of the spiral grooved-wheel fertilizer feeder and uses a rack experiment to compare the fertilizer feeding performance of the spiral and straight grooved-wheel fertilizer feeders. The final section summarizes this study and provides the conclusions.

\section{Methodology}

\subsection{Design and modeling of the spiral grooved-wheel fertilizer feeder}

The spiral grooved-wheel fertilizer feeder includes a spiral grooved-wheel, fertilizer feeding box, fertilizer feeding tongue, fertilizer feeding baffle plate, and fertilizer feeding shaft, as shown in Fig. 1. The grooved-wheel is an important structure that affects fertilizer feeding performance. In this study, the traditional straight grooved- wheel is replaced by a spiral grooved-wheel.

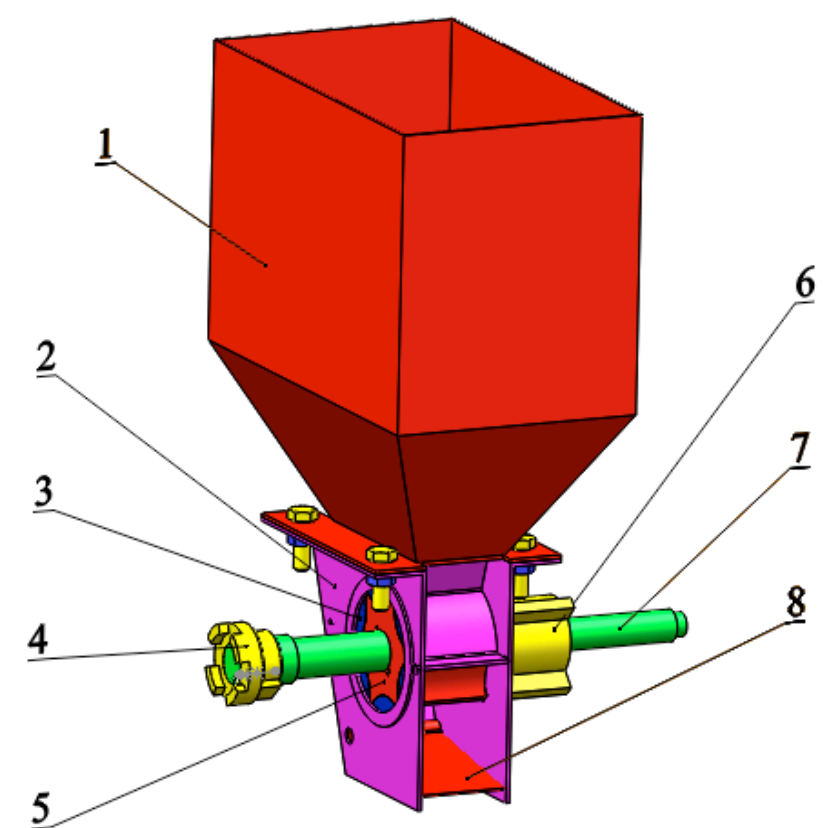

1.Fertilizer box 2. Fertilizer feeding box 3. Retainer ring 4. Couple 5. Spiral grooved-wheel 6. Fertilizer feeding baffle ring

7. Fertilizer feeding shaft 8 . Fertilizer feeding tongue

Fig. 1. Spiral groove-wheel fertilizer feeder

The fertilizer feeding box is installed below the fertilizer box. The fertilizer flows into the fertilizer feeder through the opening at the box bottom. The spiral grooved-wheel and spline retainer ring revolve with the fertilizer feeding shaft, but the fertilizer feeding baffle plate remains still, and the fertilizer feeding baffle plate and spline baffle ring can prevent the fertilizer from flowing out on the two sides. The straight grooved-wheel fertilizer feeder has a fertilizer feeding non-uniformity problem; thus, the straight groovedwheel is replaced by a spiral grooved-wheel in this study. The teeth ridge consistently appears as a constant cross section during the entire fertilizer feeding process. Originally, the teeth ridge and grooved-wheel tooth groove appear in a staggered manner. Thus, fertilizer feeding uniformity can be improved, the pulsation of the fertilizer feeding process can be reduced, and fertilizer feeding precision can be increased. 


\subsection{Design of key parameters}

\subsubsection{Diameter $d$ of the spiral grooved-wheel fertilizer feeding}

Under a certain power and revolving speed, the diameter of the spiral grooved-wheel decides the particle size of the fertilizer in the fertilizer feeding process, thereby providing a theoretical basis for guaranteeing continuous fertilizer feeding. The spiral grooved-wheel starts revolving at a certain revolving speed with the revolution of the fertilizer feeding shaft. The fertilizer stress-bearing process in the wheel groove is shown in Fig. 2.

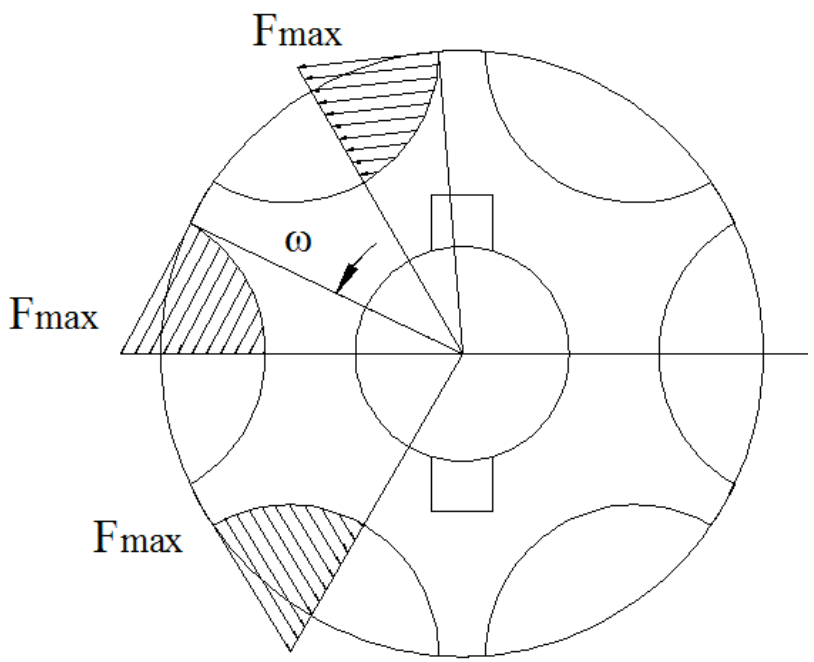

Fig. 2. Extrusion force distribution of the groove surface of the spiral grooved-wheel

Under general circumstances, the greater the fertilizer particle size is, the greater the grooved-wheel diameter is. The grooved-wheel diameter is generally $d=25-50 \mathrm{~mm}$ [22]. When power and revolving speed are known, the greater the diameter is and the smaller the extrusion force of the fertilizer feeder is. On the basis of early testing, $d=48 \mathrm{~mm}$ is used in this study. Through a fertilizer crushing force test, the minimum crushing force of the three fertilizer types is obtained as $F_{P}$. During fertilizer feeding, when the extrusion force of the fertilizer feeder applied on the fertilizer is greater than the minimum fertilizer crushing force $F_{P}$, the fertilizer is crushed, the fertilizer particle size is reduced, and fertilizer mobility decreases. These occurrences can exert a great influence on the performance of the fertilizer feeder. Thus, checking the fertilizer intensity, as shown in Equation (1), is necessary.

$$
\left\{\begin{array}{l}
T=9549 \frac{P}{n} \\
F_{\min }=\frac{2 T}{d}
\end{array}\right.
$$

Formula (1) indicates that $F_{\min } \leq F_{P}$. Therefore, when the grooved-wheel diameter is $48 \mathrm{~mm}$ in the fertilizer feeding process, fertilizer particle size can be effectively maintained with favorable fertilizer feeding performance.

\subsubsection{Working length $L$ and groove number $Z$ of the} spiral grooved-wheel

Working length $L$ of the grooved-wheel should be greater than twice the longest length of the fertilizer or the fertilizer filling will be blocked, thereby causing fertilizer feeding non-uniformity [22]. The scope of working length of the existing grooved-wheel is $30-50 \mathrm{~mm}$ [22], and the working length $L$ of the spiral grooved-wheel fertilizer feeder in this study is. The fertilizer feeding test on the grooved-wheels of different groove numbers indicates that the variable coefficient of fertilizer feeding quantity of the outer grooved-wheel fertilizer feeder is the minimum when the groove number is $Z=6$; thus, the fertilizer feeding stability is favorable [23].

\subsubsection{Shape of the groove cross section}

For convenience of fertilizer filling and discharge, the groove cross section is generally in an arch shape, and the shallowest groove depth should not be smaller than half of the fertilizer thickness [22]. In consideration of groovedwheel diameter and processing technology, the groove shape in this study is shown in Fig. 3.

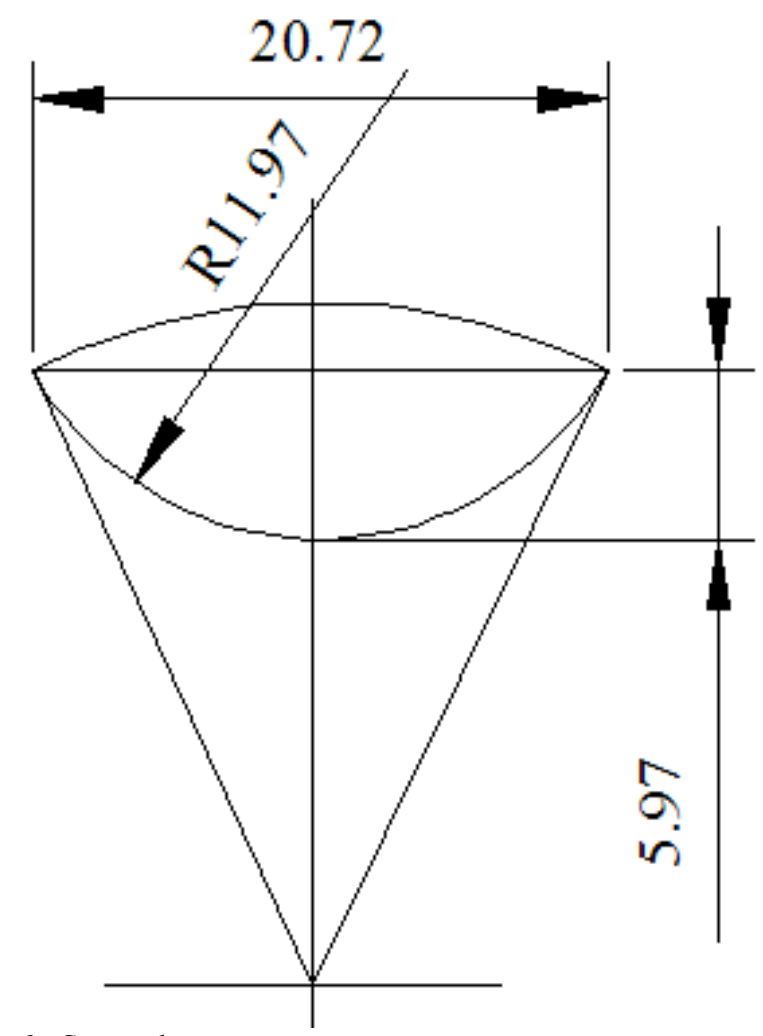

Fig. 3. Groove shape

\subsubsection{Determination of the helix angle of the spiral grooved-wheel}

In the spiral grooved-wheel, when diameter, length and groove number are determined, the outer circumference of the spiral grooved-wheel is unfolded along one generatrix (as shown in Fig. 4). The included angle $\lambda$ between the teeth ridge tangent of the spiral grooved-wheel and the horizontal direction is the helix angle. As the helix angle increases continuously, the number of longitudinal teeth ridges participating in the fertilizer feeding continuously changes, and the grooved-wheel's working length $L$ and helix angle $\lambda$ have the following relationship.

$0<L \cot \lambda \leq L$

When the projection of teeth ridges on the end face satisfies Equation (3), the teeth ridges always appear as a 
constant cross section during fertilizer feeding, and the following relationship exists.

$$
L \cot \lambda=\frac{\pi d}{z}
$$

Where $L$ is the effective working length, $d$ is the diameter of the spiral grooved-wheel, and $Z$ is the teeth number of the spiral grooved-wheel.

When $L=45, d=48, Z=6, \lambda=60.83^{\circ}$ can be obtained by substituting it into Equation (3).

Analysis shows that during the revolution process of the spiral grooved-wheel, the fertilizer feeding faces of the grooved-wheel teeth ridges participating in the fertilizerfeeding process are reduced in the axial direction at any time as the helix angle increases. When $\lambda$ increases to $60.83^{\circ}$, the fertilizer feeding face of the grooved-wheel, which participates in the fertilizer feeding, is a complete axial section of teeth ridges, and the grooved-wheel always appears as a constant cross section during the fertilizer feeding process, thereby guaranteeing fertilizer feeding continuity and improving uniformity. When $\lambda$ is greater than $60.83^{\circ}$, teeth ridges and grooves appear in a staggered manner during fertilizer feeding.

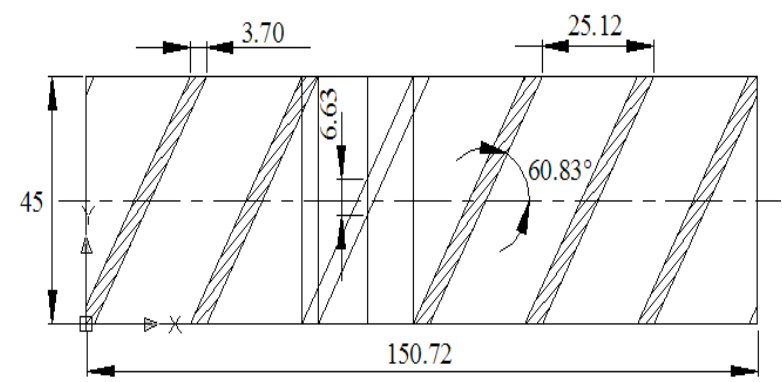

Fig. 4. Schematic of circumferential unfolding of the spiral groovedwheel

Analysis shows that during the revolution process of the spiral grooved-wheel, the fertilizer feeding faces of the grooved-wheel teeth ridges participating in the fertilizer feeding process are reduced in the axial direction at any time as the helix angle increases. When $\lambda$ increases to $60.83^{\circ}$, the fertilizer feeding face of the grooved-wheel, which participates in the fertilizer feeding, is a complete axial section of teeth ridges, and the grooved-wheel always appears as a constant cross section during the fertilizer feeding process, thereby guaranteeing fertilizer feeding continuity and improving uniformity. When $\lambda$ is greater than $60.83^{\circ}$, teeth ridges and grooves appear in a staggered manner during fertilizer feeding.

\subsubsection{Fertilizer feeding quantity of the spiral grooved - wheel}

The relationships of the fertilizer feeding quantity when the grooved-wheel revolves for one revolution with crosssectional area $A$ of the groove, groove number $Z$, effective working length $L$ of the grooved-wheel, average thickness $c(n)$ of the fertilizer driving layer, and revolving speed $n$ of the fertilizer feeding shaft are as follows:

$$
q=\pi d L \gamma\left(\frac{\alpha(n) f}{t}+c(n)\right)
$$

where $d$ is the diameter of the outer grooved-wheel; $L$ is the working length of the outer grooved-wheel; $\alpha(n)$ is the fertilizer filling coefficient in the groove, which is related to revolving speed; $f$ is the end face area of the groove; $\gamma$ is fertilizer density; $t$ is the pitch between groove teeth; and $c(n)$ is the driving layer characteristic coefficient or calculated thickness.

\subsubsection{Fertilizer feeding uniformity}

The pulsation of the outer grooved-wheel fertilizer feeder refers to the fact that fertilizer feeding quantity presents a certain regular change in each fertilizer feeding cycle due to the mechanical structure of the outer grooved- wheel when the revolving speed is low and the fertilizer feeding quantity is small. Change rate $K$ of fertilizer feeding quantity in the fertilizer feeding process is used to measure fertilizer feeding pulsation in reality. $K$ refers to the ratio of the mean absolute value of the difference between average fertilizer feeding quantity at any sampling time and average fertilizer feeding quantity within time $t$ to the average value of average fertilizer feeding quantity within the sampling time, as shown in Formula (5). The greater the $K$ value is, the greater the pulsation is and the poorer the fertilizer feeding uniformity is (and vice versa).

$$
K=\frac{\frac{1}{n} \sum_{i=1}^{n}\left|q_{i}-q_{a v}\right|}{q_{a v}} \times 100 \%
$$

Where $q_{i}$ is fertilizer feeding quantity at any time within the sampling time; $q_{a v}$ is average fertilizer feeding quantity within the sampling time.

\subsection{Modeling and simulation of the spiral grooved-wheel fertilizer feeder}

The fertilizer feeder mainly consists of a fertilizer box, fertilizer feeder, fertilizer feeding box, fertilizer feeding tongue, fertilizer feeding baffle plate, and fertilizer receiving tube. The structure of the fertilizer feeder is an important factor that affects fertilizer feeding uniformity. On the basis of early-stage design, three grooved-wheel structures with different helix angles are adopted for simulation and comparison, as shown in Fig. 5.
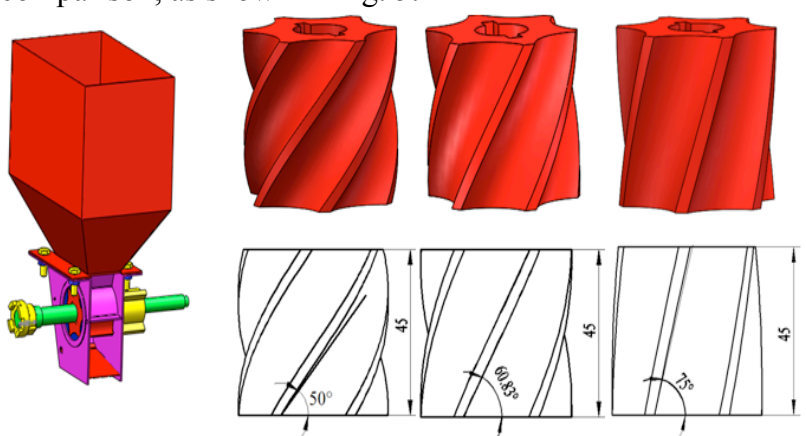

$\begin{array}{ll}\text { (a) } \lambda=50^{\circ} & \text { (b) } \lambda=60.83^{\circ} \\ \text {-wheel fertilizer feeder graph }\end{array}$

Fig. 5. Spiral grooved-wheel fertilizer feeder graph

(c) $\lambda=75^{\circ}$

\subsubsection{Parameter determination}

The parameters of the materials and fertilizers in the components of the fertilizer feeder are acquired through actual measurement and from related studies [18,24,25]. The parameter settings are is shown in Table. 1. 
Table 1. Material characteristic parameters

\begin{tabular}{|c|c|c|}
\hline Property & Parameter & Value \\
\hline Fertilizer & $\begin{array}{l}\text { Particle size } d /(\mathrm{mm}) \\
\text { Density } \rho /\left(\mathrm{kg} \cdot \mathrm{m}^{-3}\right) \\
\text { Poisson's ratio } v \\
\text { Elasticity modulus } \mathrm{G} /(\mathrm{Pa})\end{array}$ & $\begin{array}{l}2.97 \\
1333 \\
0.25 \\
9.2 \times 10^{6}\end{array}$ \\
\hline Shell & $\begin{array}{l}\text { Density } \rho /\left(\mathrm{kg} \cdot \mathrm{m}^{-3}\right) \\
\text { Poisson's ratio } v \\
\text { Elasticity modulus } \mathrm{G} /(\mathrm{Pa})\end{array}$ & $\begin{array}{l}7850 \\
0.24 \\
196\end{array}$ \\
\hline $\begin{array}{l}\text { Grooved- } \\
\text { wheel }\end{array}$ & $\begin{array}{l}\text { Density } \rho /\left(\mathrm{kg}^{-\mathrm{m}^{-3}}\right) \\
\text { Poisson's ratio } v \\
\text { Elasticity modulus } \quad \mathrm{G} /(\mathrm{Pa}) \\
\end{array}$ & $\begin{array}{l}7200 \\
0.25 \\
1.4 \times 10^{11}\end{array}$ \\
\hline Interaction & $\begin{array}{l}\text { Static friction coefficient between } \\
\text { fertilizer and fertilizer box } \mu_{1} \\
\text { Dynamic friction coefficient between } \\
\text { fertilizer and fertilizer box } v_{1} \\
\text { Static friction coefficient between } \\
\text { fertilizer and grooved-wheel } \mu_{2} \\
\text { Dynamic friction coefficient between } \\
\text { fertilizer and grooved- wheel } v_{2} \\
\text { Static friction coefficient between } \\
\text { fertilizers } \mu_{3} \\
\text { Dynamic friction coefficient between } \\
\text { fertilizers } v_{3} \\
\text { Recovery coefficient between fertilizer } \\
\text { and grooved-wheel } e_{1}\end{array}$ & $\begin{array}{l}0.278 \\
0.152 \\
0.307 \\
0.168 \\
0.906 \\
0.495 \\
0.318\end{array}$ \\
\hline Others & Gravitational acceleration $g /\left(\mathrm{m} / \mathrm{s}^{2}\right)$ & 9.8 \\
\hline
\end{tabular}

3.3.2 Fertilizer feeding simulation of the spiral groovedwheel fertilizer feeder

The spiral grooved-wheel under different helix angles obtained through simulation when the revolving speed of the fertilizer feeder is $40 \mathrm{r} / \mathrm{min}$. According to the figure, under similar conditions, when the helix angle increases to $60.83^{\circ}$, fertilizers at the compulsion and driving layers always have a complete longitudinal teeth ridge thickness along the direction of the parallel axis, namely, during the entire fertilizer feeding motion process of the spiral grooved-wheel. When the first teeth ridge in the direction of the same parallel axis moves to the final longitudinal teeth ridge thickness, the next teeth ridge starts moving. When the teeth ridge moves to the first complete longitudinal teeth ridge thickness, the motion of the last teeth ridge ends. The effective fertilizer filling length when the spiral groovedwheel revolves for one revolution is always the difference between spiral grooved-wheel length and longitudinal teeth ridge thickness. The effective fertilizer filling length presents a continuous distribution during the entire fertilizer feeding process. Fertilizers are uniformly discharged, thereby improving fertilizer feeding uniformity and precision.

\subsubsection{Fertilizer state in the fertilizer feeding zone}

When the spiral grooved-wheel fertilizer feeder revolves at a certain revolving speed, fertilizers begin to flow, and fertilizers in the spiral grooved-wheel's groove are forcefully driven along teeth ridges during the grooved-wheel revolution process. Their speed is approximate to the grooved-wheel revolving speed, and they move toward the teeth ridge direction with minimum resistance. Thus, compulsion and driving layers are formed. Fertilizers at the compulsion layer transmit the motion to upper-layer fertilizers, contacting them through frictional force between fertilizers, thereby forming the driving layer. The motion status of fertilizers at this layer is relatively complicated. Under frictional forces among the compulsion layer, fertilizer particles, spiral grooved-wheel, and shell, fertilizer motion speed decreases from the revolution center outward. Fig. 6 shows the fertilizer particle distribution feature map in the spiral grooved-wheel under different helix angles obtained through simulation when the revolving speed of the fertilizer feeder is $40 \mathrm{r} / \mathrm{min}$. According to the figure, under similar conditions, when the helix angle increases to $60.83^{\circ}$, fertilizers at the compulsion and driving layers always have a complete longitudinal teeth ridge thickness along the direction of the parallel axis, namely, during the entire fertilizer feeding motion process of the spiral grooved-wheel. When the first teeth ridge in the direction of the same parallel axis moves to the final longitudinal teeth ridge thickness, the next teeth ridge starts moving. When the teeth ridge moves to the first complete longitudinal teeth ridge thickness, the motion of the last teeth ridge ends. The effective fertilizer filling length when the spiral groovedwheel revolves for one revolution is always the difference between spiral grooved-wheel length and longitudinal teeth ridge thickness. The effective fertilizer filling length presents a continuous distribution during the entire fertilizer feeding process. Fertilizers are uniformly discharged, thereby improving fertilizer feeding uniformity and precision.

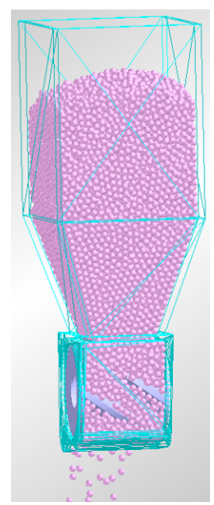

(a) $\lambda=50^{\circ}$

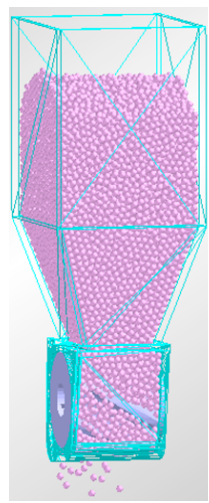

(b) $\lambda=60.83^{\circ}$

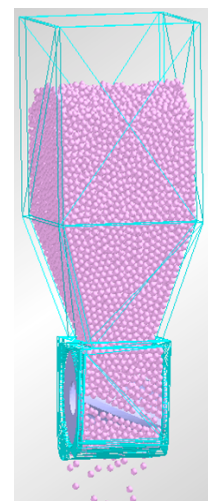

(c) $\lambda=75^{\circ}$
Fig. 6 Forms of the fertilizer feeding zone under different helix angles $(\mathrm{t}=5 \mathrm{~s})$

\subsubsection{Mechanical properties of fertilizers in the fertilizer feeding zone and fertilizer feeding mechanism}

The motion of fertilizer particles in the fertilizer feeding zone is influenced by multiple factors. The motion of the spiral grooved-wheel fertilizer feeder at the fertilizer layer is complicated. Fertilizers at the compulsion layer are greatly influenced by the use of the spiral grooved-wheel. Thereforefertilizer particles at the compulsion layer are used as study objects, and a $\tau-n$ coordinate system is established along tangent direction $\tau$ and normal direction $n$ of teeth ridges to study the motion status of fertilizers in the groove. Under the joint action of various forces, fertilizer particles slide downward along the groove direction. They also revolve with the spiral grooved-wheel. The absolute motion of fertilizer particles is a result of the above-mentioned two motions. The minimum speed of fertilizer particles during the motion process is close to the minimum speed in the spiral grooved-wheel's groove. The stress-bearing analysis is shown in Fig. 7. Where $F_{P}$ is the extrusion force applied by the grooved-wheel to fertilizers, $F_{f 1}$ is the frictional force 
between the fertilizer and grooved-wheel, $F_{f 2}$ is the frictional force between fertilizers, and $F_{L}$ is the centrifugal force of fertilizers.

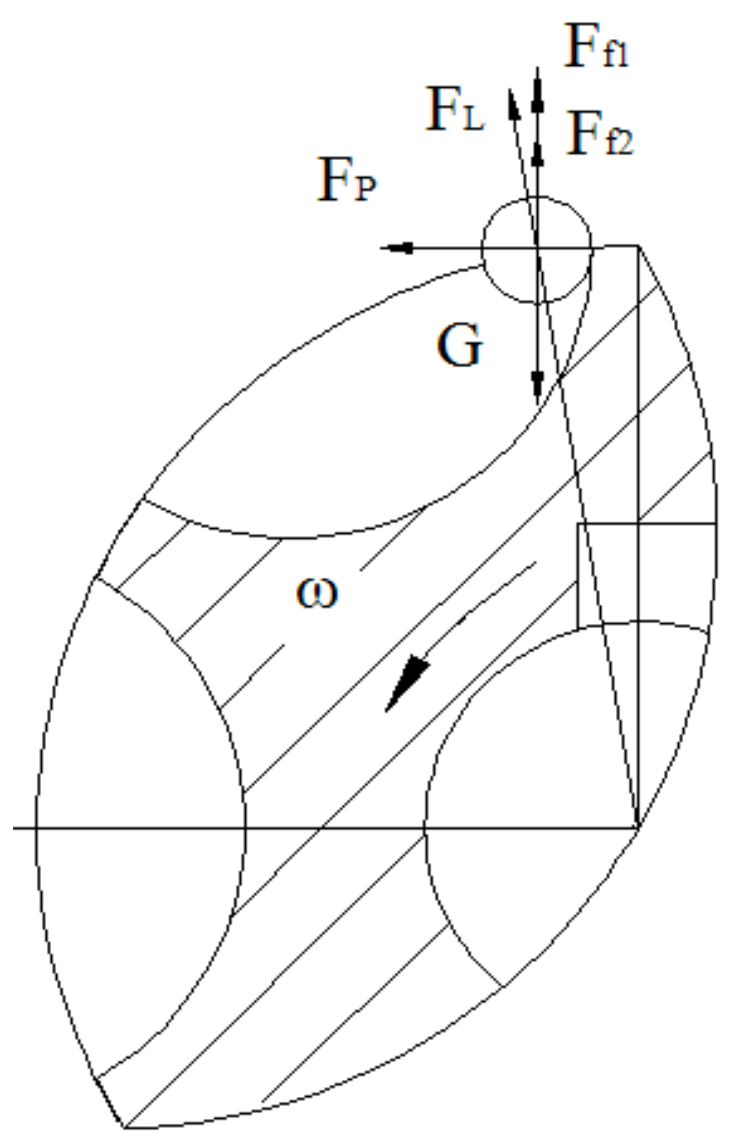

Fig. 7. Stress-bearing analysis of fertilizer particles at the driving layer

In consideration of the stress-bearing conditions of single fertilizer particles, $F_{f 2}=0 \mathrm{~N}$, the following equations can be obtained.

$$
\left\{\begin{array}{c}
m a_{y}=F_{f 1}-m g \cos \theta \\
m \omega^{2} v_{r}+F_{P}=m g \sin \theta \\
a_{y}=\frac{d^{2} s_{r}}{d^{2} t} \\
v_{r}=\frac{d s_{r}}{d t} \\
F_{f 1}=F_{P} t g \varphi
\end{array}\right.
$$

Where $m$ is the mass of a single fertilizer particle, $k g ; r$ is the distance from the center of gravity of fertilizer particles to the grooved-wheel center, $m ; \omega$ is the grooved-wheel revolving speed, $\mathrm{rad} / \mathrm{s} ; \theta$ is the included angle between the radius of the grooved-wheel where fertilizers are located and the horizontal direction, ${ }^{\circ} ;$ and $a_{y}$ is the tangential acceleration of fertilizers along the outer wall of the grooved-wheel, $\mathrm{m} / \mathrm{s}^{2}$.

The following can be obtained by organizing Equation (6)a result of the above-mentioned two motions.

$$
\frac{d s_{r}}{d t}=\frac{\left(g \sin \theta-\omega^{2} r\right) \operatorname{tg} \varphi-g \cos \theta}{2 \omega \operatorname{tg} \varphi}
$$

The ultimate fertilizer filling speed is $v_{\text {rmax }}=\frac{d / \cos \lambda-(b / 2) \operatorname{ctg} \theta}{\sqrt{b / g \sin \theta}}$

Where $b$ is fertilizer thickness, $\mathrm{mm} ; d$ is the groove chord length, $\mathrm{mm} ; \mathrm{c}$ is the half width of fertilizers, $\mathrm{mm}$; and $\lambda$ is the grooved-wheel helix angle, $\left(^{\circ}\right)$.

\section{Result analysis and discussion}

\subsection{Analysis and discussion of simulation results}

After the simulation, a statistical analysis of related data is conducted. The helix angle greatly affects fertilizer feeding uniformity. Furthermore, pulsation is obvious under a low revolving speed and small fertilizer feeding quantity. Therefore, data on $P$ fertilizer in the spiral grooved-wheel under different helix angles at a revolving speed $30 \mathrm{r} / \mathrm{min}$ are used as study objects, as shown in Figs. 8 and 9.

As shown in Fig. 8, when the revolving speed is low, the fertilizer feeding quantity per revolution increases with the helix angle of the spiral grooved-wheel. When the helix angle is $60.83^{\circ}$, the fertilizer feeding quantity reaches the maximum value; the fertilizer feeding quantity presents tendency decline as the helix angle further increases. When the helix angle of the spiral grooved-wheel increases to $90^{\circ}$, the wheel-groove is perpendicular to the grooved-wheel axis, which enlarges the fertilizer self-flow layer in the fertilizer feeder while reducing the compulsion layer. Fertilizers in the fertilizer box flow along the wheel-groove due to their own gravity, and the revolving speed exerts a minor influence on fertilizer feeding quantity.

According to Fig. 9, the change rate of the fertilizer feeding quantity of the spiral grooved-wheel fertilizer feeder changes as the helix angle increases, and the change rate of the fertilizer feeding quantity increases with the helix angle as well. When the helix angle is larger than $45^{\circ}$, the change rate of the fertilizer feeding quantity presents a decline and reaches the minimum value when the helix angle is $60.83^{\circ}$. The fertilizer feeding uniformity is the best at this time. As the helix angle continues to increase, the change rate also increases, but the uniformity becomes poor.

\subsection{Analysis and discussion of test results}

To conduct a comparative analysis of the fertilizer feeding performance of the spiral and straight grooved-wheel feeders under optimal structural parameters, three fertilizer types commonly used in Xinjiang are utilized as

test materials in this study. The spiral outer grooved-wheel and straight grooved-wheel under a helix angle of $60.83^{\circ}$ are used as test objects, and a self-made performance test bench of fertilizer feeders is used as the test equipment (Fig. 10). Thus, we are able to test two fertilizer feeders with different outer grooved-wheel structures.

For a comparative analysis of the fertilizer feeding performance of the two fertilizer feeders, the fertilizer box is initially filled with fertilizers. The working time and revolving speed of the fertilizer feeders are set through a touch screen. A conveyor belt is set below the fertilizer receiving tube, and the motion time and speed of the conveyor belt are also set on the touch screen. The fertilizer feeding quantities of the two fertilizer feeders are measured at a speed of $30 \mathrm{r} / \mathrm{min} \sim 150 \mathrm{r} / \mathrm{min}$, and the measured data are shown in Tables. 2 and 3. 

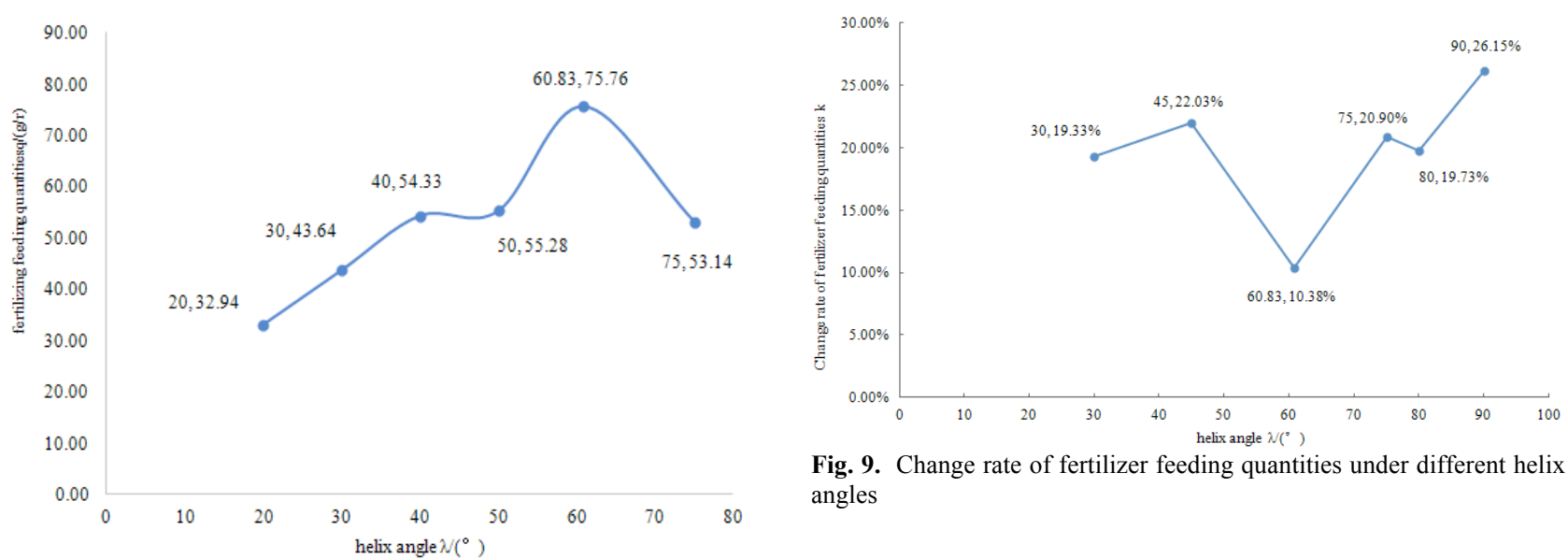

Fig. 9. Change rate of fertilizer feeding quantities under different helix angles

Fig. 8. $\quad \mathrm{P}$ fertilizer feeding quantities under different helix angles $(30 \mathrm{r} / \mathrm{min})$
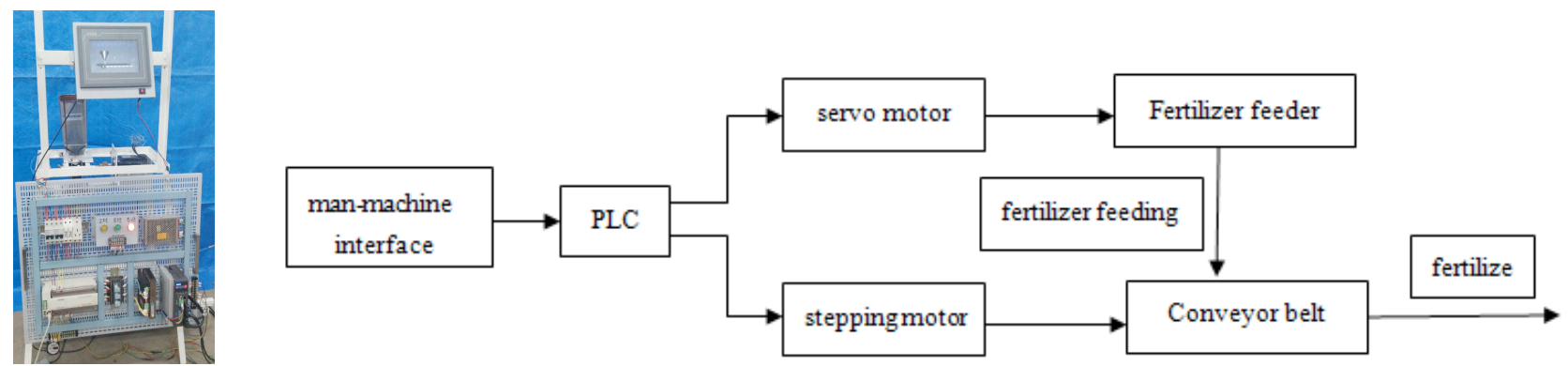

Fig. 10. Test bench of grooved-wheel fertilizer feeders and block schematic

Table. 2. Determination of fertilizer feeding quantities of different grooved-wheels at arbitrary time $(30 \mathrm{r} / \mathrm{min})$

\begin{tabular}{c|l|l|l|l|l|l|l}
\hline Revolving speed & $1.5 \mathrm{~s}$ & $2.5 \mathrm{~s}$ & $3.0 \mathrm{~s}$ & $3.5 \mathrm{~s}$ & $5.0 \mathrm{~s}$ & $5.5 \mathrm{~s}$ & Average value \\
\hline $\begin{array}{c}\text { Spiral grooved- wheel } \\
\begin{array}{c}\text { Straight grooved- } \\
\text { wheel }\end{array}\end{array}$ & 34.320 & 69.583 & 88.675 & 106.096 & 159.704 & 177.661 & 32.358 \\
\hline
\end{tabular}

Table. 3. Fertilizer feeding quantities of two grooved-wheels at different revolving speeds

\begin{tabular}{|c|c|c|c|c|c|c|c|c|c|c|c|c|c|}
\hline $\begin{array}{l}\text { Revolving } \\
\text { speed }\end{array}$ & 30 & 40 & 50 & 60 & 70 & 80 & 90 & 100 & 110 & 120 & 130 & 140 & 150 \\
\hline $\begin{array}{c}\text { Spiral } \\
\text { grooved - } \\
\text { wheel }\end{array}$ & 32.36 & 36.79 & 45.94 & 53.44 & 61.569 & 71.31 & 78.34 & 87.25 & 89.17 & 81.95 & 93.34 & 121.40 & 130.48 \\
\hline $\begin{array}{l}\text { Straight } \\
\text { grooved- } \\
\text { wheel }\end{array}$ & 23.28 & 29.87 & 36.73 & 43.58 & 49.250 & 56.57 & 62.77 & 68.97 & 70.54 & 64.31 & 72.26 & 92.58 & 99.43 \\
\hline
\end{tabular}

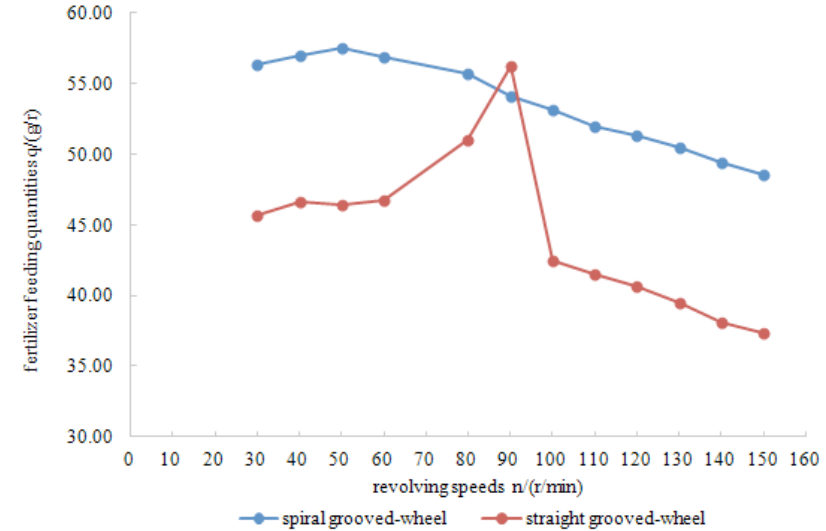

Fig. 11. Comparison of fertilizer feeding quantities of two groovedwheels at different revolving speeds
Table. 3 shows that the fertilizer feeding quantities of both grooved-wheels present increasing tendencies as the revolving speed increases, and the fertilizer feeding quantity of the spiral grooved-wheel is larger than that of the straight grooved-wheel.

Fig. 11 shows a comparison of the fertilizer feeding quantities of the two grooved-wheels at different revolving speeds. The fertilizer feeding quantities of both groovedwheels per revolution decline as the revolving speed increases, but the fertilizer feeding quantity of the straight grooved-wheel initially presents an increase then a decrease at the speed of $90 \mathrm{r} / \mathrm{min}$ mainly because the fertilizer filling coefficient in the grooved-wheel continuously increases with the revolving speed, and the filling coefficient reaches the maximum value at a speed of $90 \mathrm{r} / \mathrm{min}$. As the revolving speed continues to increase, the filling coefficient 
continuously decreases, and the fertilizer feeding quantity per revolution also decreases. As the revolving speed increases, the fertilizer feeding quantity per revolution of the spiral grooved-wheel decreases, but the overall fertilizer feeding quantity per revolution remains higher than that of the straight grooved-wheel, indicating that the regulatory scope of the revolving speed of the spiral grooved-wheel is wider for fertilizer feeding quantity.
Table. 2 shows the calculated fertilizer feeding quantities of the straight and spiral grooved-wheels (with a helix angle of $60.83^{\circ}$ ) within a certain time at a revolving speed of $30 \mathrm{r} / \mathrm{min}$. and are obtained following Formula (5), where $K_{1}$ is the change rate of the fertilizer feeding quantity of the spiral grooved-wheel and $K_{2}$ is that of the straight groovedwheel. Similarly, the change rates of fertilizer feeding quantities at other revolving speeds can be calculated through the statistics of the test data, as shown in Table. 4.

Table. 4. Change rates of fertilizer feeding quantities of the two grooved-wheels under different revolving speeds

\begin{tabular}{|c|c|c|c|c|c|c|c|c|c|c|c|c|c|}
\hline $\begin{array}{l}\text { Revolving } \\
\text { speed }\end{array}$ & 30 & 40 & 50 & 60 & 70 & 80 & 90 & 100 & 110 & 120 & 130 & 140 & 150 \\
\hline $\begin{array}{l}\text { Spiral } \\
\text { grooved- } \\
\text { wheel }\end{array}$ & $8.83 \%$ & $9.52 \%$ & $9.37 \%$ & $7.81 \%$ & $6.48 \%$ & $3.86 \%$ & $4.54 \%$ & $3.53 \%$ & $3.82 \%$ & $2.51 \%$ & $2.74 \%$ & $2.52 \%$ & $2.38 \%$ \\
\hline $\begin{array}{l}\text { Straight } \\
\text { grooved } \\
\text { wheel }\end{array}$ & $22.5 \%$ & $16.8 \%$ & $13.8 \%$ & $12.5 \%$ & $8.88 \%$ & $6.55 \%$ & $6.65 \%$ & $5.89 \%$ & $5.03 \%$ & $4.98 \%$ & $5.17 \%$ & $4.82 \%$ & $4.37 \%$ \\
\hline
\end{tabular}

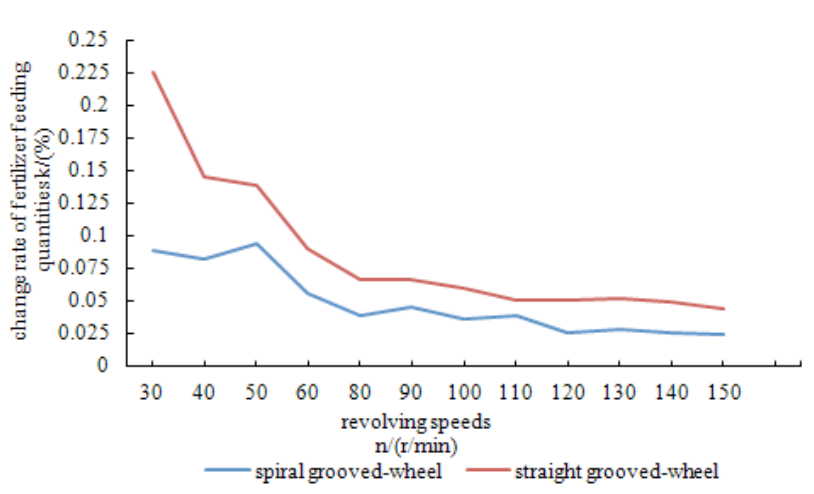

Fig. 12. Comparison of the change rates of the fertilizer feeding quantities of the two grooved-wheels under different revolving speeds

Fig. 12 shows a comparison of change rates of the fertilizer feeding quantities of the two grooved-wheels under different revolving speeds. The change rates of the fertilizer feeding quantities of the spiral and straight grooved-wheels decline with revolving speed. The change rate of the fertilizer feeding quantity of the spiral grooved-wheel is smaller than that of the straight grooved-wheel on the whole, and this phenomenon is becomes highly obvious under a low revolving speed, indicating that the fertilizer feeding uniformity of the spiral grooved-wheel is better than that of the straight grooved-wheel; it can solve the pulsation problem of the straight grooved-wheel fertilizer feeder under a low revolving speed.

\section{Conclusions}

To reduce the fertilizer feeding pulsation of the outer straight grooved-wheel fertilizer feeder and improve fertilizer feeding uniformity, key parameters of a spiral groovedwheel were designed, and the fertilizer feeding mechanism of the spiral grooved-wheel under different helix angles was analyzed using the discrete element software. The fertilizer feeding performance of the straight and spiral groovedwheels was compared and verified using a test bench. The following conclusions were obtained.
(1) Under the same revolving speed, the fertilizer feeding quantity per revolution of the spiral grooved-wheel under the optimal helix angle is the maximum, with the minimum change rate in the fertilizer feeding quantity and the best uniformity.

(2) Under different revolving speeds, the fertilizer feeding quantities of the spiral and straight grooved-wheels increase. The fertilizer feeding quantity of the spiral groovedwheel is larger than that of the straight grooved-wheel on the whole. Moreover, the fertilizer feeding uniformity of the spiral grooved-wheel fertilizer feeder is better than that of the straight grooved-wheel fertilizer feeder, which is particularly obvious under a low revolving speed.

(3) As the revolving speed increases, the revolving speed at which the fertilizer feeding quantity per revolution of the spiral grooved-wheel fertilizer decreases is lower than that of the straight grooved-wheel fertilizer feeder. However, the fertilizer feeding quantity per revolution remains higher than that of the straight grooved-wheel overall. The adjustment scope of the spiral grooved-wheel for fertilizer feeding quantity by the revolving speed is wide.

The study's results can effectively ameliorate the fertilizer feeding pulsation problem caused by the traditional grooved-wheel structure and can be important for the improvement of fertilizer feeding uniformity and precision. Based on the theoretical design, the particle discrete element method and a test bench were used in this study to investigate the fertilizer feeding performance of the spiral grooved-wheel fertilizer feeder. Given that an actual farmland environment was not used in this work, this study has certain limitations. In the future, fertilizer feeding performance tests could be conducted in an actual farmland environment to verify the actual fertilizer feeding performance of the spiral grooved-wheel fertilizer feeder.

\section{Acknowledgements}

The study was supported by the National Natural Science Foundation of China (Grant No.51365048)

This is an Open Access article distributed under the terms of the Creative Commons Attribution License

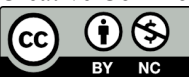




\section{References}

1. Shi, Y., Chen, M., Wang, X., "Analysis and experiment of fertilizing performance for precision fertilizer applicator in rice and wheat fields". Transaction of the Chinese Society for Agricultural Machinery, 48(07), 2017, pp. 97-103.

2. Zhu, Q., Wu, G., Chen, L., "Influences of structure parameters of straight flute wheel on fertilizing performance of fertilizer apparatus". Transactions of the Chinese Society of Agricultural Engineering, 34(18), 2018, pp. 12-20.

3. BOUROUBI Y., TREMBLAY N., VIGNEAULT P., "Fuzzy logic approach for spatially variable nitrogen fertilization of corn based on soil,crop and precipitation information". Computational Science and Its Application, 6782, 2011, pp. 356-368.

4. Gu, Y., Yuan, J., Liu, C., "FIS-based method to generate bivariate control parameters regulation sequence for fertilization". Transactions of the Chinese Society of Agricultural Engineering, 27(11), 2011, pp. 134-139.

5. CHATTHA H S., ZAMAN Q U., CHANG Y K., "Variable rate spreader for real-time spot-application of granular fertilizer in wild blueberry". Computers and Electronics in Agriculture, 100, 2014, pp. $70-78$.

6. Wang, X., Chen, M., Sun, G., "Design and test of control system on variable fertilizer applicator for winter wheat". Transactions of the Chinese Society of Agricultural Engineering, 31(Supp. 2), 2015, pp. 88-92. (in Chinese)

7. An, X., Wang, X., Fu, W., "Design and experiment of fertilizer amount control algorithm in four factors variable rate fertilization system". Transaction of the Chinese Society for Agricultural Machinery, 49(S1), 2018, pp. 149-154.

8. M.R. Maleki., J.F. Jafari., M.H. Raufat., A.M. Mouazen., J. De Baerdemaeker., "Evaluation of seed distribution uniformity of a multi-flight auger as a grain drill metering device". Biosystems Engineering, 94(4), 2006, pp. 535-543.

9. Guler. Effects of flute diameter., fluted roll length., and speed on alfalfa seed flow". Applied engineering in agriculture, 21(1), 2005, pp. $5-7$.

10. I Ozturk., Y Yildirim., S Hinislioglu., "Optimization of seed flow evenness of fluted rolls used in seed drills by taguchi method". Scientific Research and Essays, 7(1), 2012, pp. 78-85.

11. Valentin Dan CRISAN., Victor ROS., "Comparative analysis of distribution uniformity on plain and inclined fluted rollers". Bulletin UASVM Agriculture, 69(1), 2012, pp. 157-162.

12. Su, N., Xu, T., Song, L., "Variable rate fertilization system with adjustable active feed-roll length". International Journal of Agricultural and Biological Engineering, 8(4), 2015, pp. 19-26.

13. Kara M., Bayhan A K., Ozsert I., Yildirim,. "Performance of fluted roll metering devices in seed drills with ammonium sulphate and diammonium phosphate". Applied Engineering in Agriculture, 26(2), 2010, pp. 197-201.
14. Wang, X., Zhao, C., Meng, Z., Chen, L., "Design and experiment of variab1e rate fertilizer applicator". Transactions of the Chinese Society of Agricultural Engineering, (5), 2004, pp. 114-117. (in Chinese)

15. Chen, H., Zhang, S., Wang, L., "A set of multi-functional control system for variable rate technologies in precision agriculture". Journal of Agricultural Mechanization Research, 36(01), 2014, pp. 210-213.

16. Dun, G., Chen, H., Feng, Y., "Parameter optimization and test of key parts of fertilizer allocation device based on EDEM software". Transactions of the Chinese Society of Agricultural Engineering, (7), 2016, pp. 36-42. (in Chinese)

17. Yuan, J., Liu, Q., Liu, X., Zhang T., "Granular multi-lows fertilization process simulation and tube structure optimization in nutrient proportion of variable rate fertilization". Transaction of the Chinese Society for Agricultural Machinery, (11), 2014, pp. 84-87. (in Chinese)

18. Dun, G., Yu, C., Yang, Y., "Discharging characteristic test of outergroove wheel fertilizer and parameter optimization of fertilizer tongue by discrete element simulation". Journal of Hunan Agricultural University (Natural Sciences), 44(06), 2018, pp. 661665.

19. Chen, X., Luo, X., Wang, Z., "Design and experiment of a fertilizer distribution apparatus with double-level screws". Transactions of the Chinese Society of Agricultural Engineering, 31(3), 2015, pp. 10-16.

20. Liu, C., Zang, Y., Luo, X., Zeng, S., "Design and experiment of spiral grooved wheel for rice direct seeding machine”. Journal of Shenyang Agricultural University, 47(06), 2016, pp. 734-739.

21. Tian, L., Wang, J., Tang, H., "Design and performance experiment of helix grooved rice deeding device". Transaction of the Chinese Society for Agricultural Machinery, 47(05), 2016, pp. 46-52.

22. Chinese academy of agriculture mechaniration sciences.,

"Agricultural machinery handbook". Beijing: China Agricultural science and technology press, China, 2007

23. Pan, S., Zhao, Y., Jin, L., "Design and experimental research of external grooved wheel fertilizer apparatus of 2BFJ-6 type variable rate fertilizer applicator". Journal of Chinese Agricultural Mechanization, (1), 2016, pp. 40-42.

24. Gregor, T., Sarah, J., Adrian, F., " Spray models for wave element simulations of particle coating processes". Chemical Engineering Science, 101, 2013, pp. 603-614

25. VILLETTE Sylvain., PIRON Emmanuel., MARTIN Richard., "Estimation of two-dimensional fertiliser mass flow distributions by recording granule impacts".Biosystems Engineering, 115(4), 2013, pp. 463-473 